\title{
АНАЛИЗ МАЛОЗНАЧИТЕЛЬНОСТИ В ПРОИЗВОДСТВЕ ПО ДЕЛАМ ОБ АДМИНИСТРАТИВНЫХ ПРАВОНАРУШЕНИЯХ
}

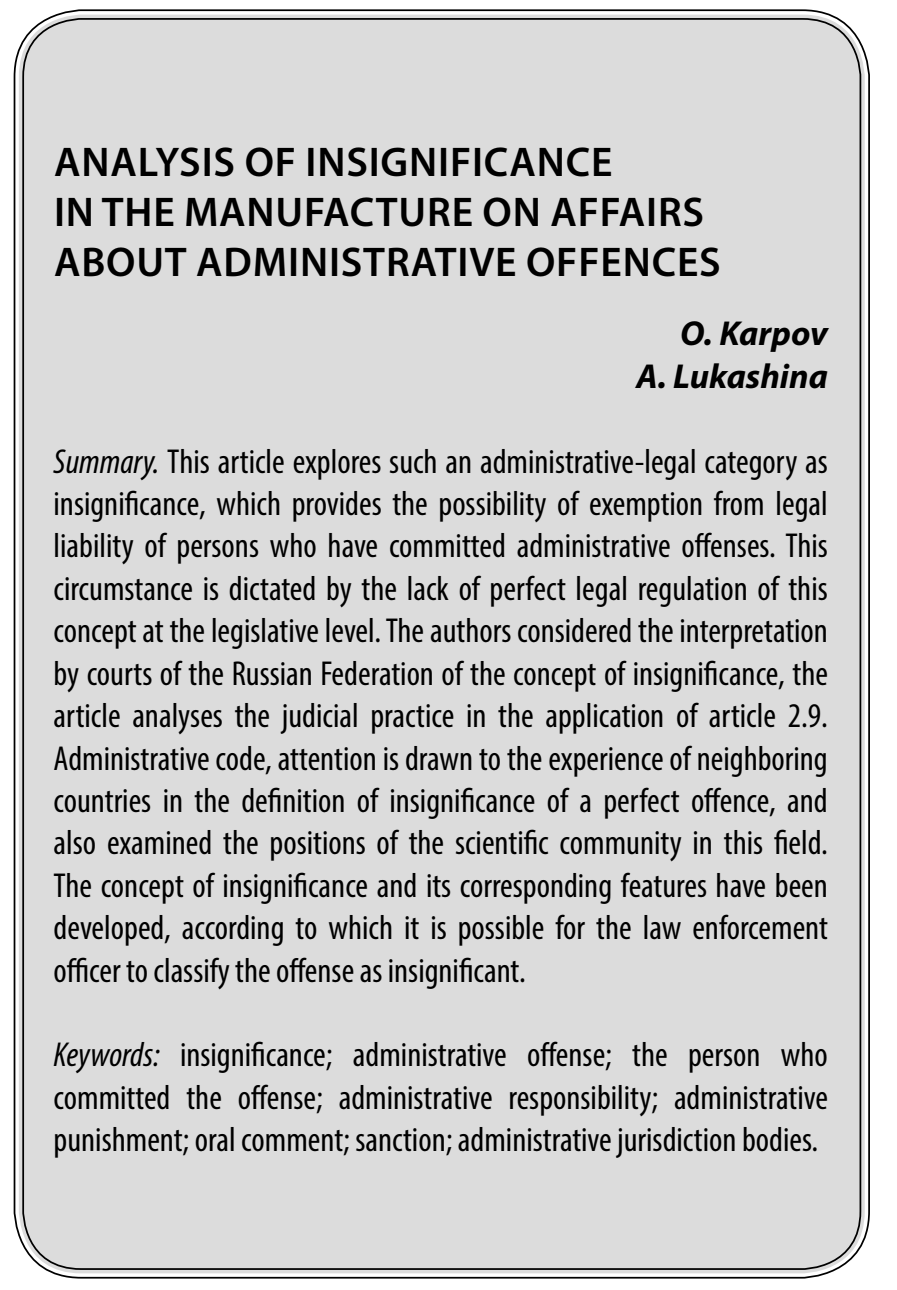

H а сегодняшний день для нашей страны характерна тенденция к увеличению числа совершаемых административных правонарушений. По общему правилу данное негативное как для государства, так и для членов общества явление дестабилизирует управленческие отношения, нарушает правопорядок в целом, повышает негативные настроения в социуме. Вследствие этого лицо, совершившее правонарушение, привлекается к административной ответственности, претерпевает определенную меру наказания, и в этом реализуется его порицание со стороны государства.

В некоторых случаях деяние формально содержит в себе все признаки состава административного правонарушения, а с точки зрения реальных фактов не представляет серьезной угрозы охраняемым государством общественным отношениям. При таких обстоятельствах
Карпов Олег Вячеславович

Старший преподаватель, Владимирский филиал Российская академия народного хозяйства и государственной службы, г. Владимир okarp67@mail.ru

Лукашина Ангелина Эльчиновна

Владимирский филиал Российская академия народного хозяйства и государственной службы, 2. Владимир

Lukashina.angelina@mail.ru

Аннотация. В настоящей статье исследуется такая административно-правовая категория, как малозначительность, которая предоставляет возможность освобождения от юридической ответственности лиц, совершивших административные правонарушения. Данное обстоятельство продиктовано отсутствием совершенного правового регулирования этого понятия на законодательном уровне. Авторами рассмотрено толкование судами Российской Федерации понятия малозначительности, проанализирована судебная практика в части применения ст. 2.9. КоАП РФ, обращено внимание на опыт стран ближнего зарубежья в определении понятия малозначительности совершенного правонарушения, а также изучены позиции научного сообщества в данной области. Выработаны понятие малозначительности и соответствующие ей признаки, в соответствии с которыми правоприменителю представляется возможным квалифицировать правонарушение как малозначительное.

Ключевые слова: малозначительность; административное правонарушение; лицо, совершившее правонарушение; административная ответственность; административное наказание; устное замечание; санкция; органы административной юрисдикции.

субъект административной юрисдикции в лице судьи, органа, должностного лица может применить статью 2.9. Кодекса Российской Федерации об административных правонарушениях и освободить лицо, совершившее проступок от юридической ответственности, ограничившись лишь устным замечанием, то есть, не применяя к нарушителю общественного порядка меру административного наказания [2].

Правовой механизм освобождения от ответственности ввиду малозначительности совершенного деяния не является новеллой, этот административно-правовой институт предусматривался и закреплялся еще административным законодательством РСФСР [3]. Примечательно, что данная категория, в частности изучение проблем ее применения в реальной жизни, не утратила актуальности. 
На наш взгляд, это продиктовано тем, что и в законодательстве прошлого столетия, и в действующих административно-правовых нормах отсутствует легальное определение малозначительности совершенного правонарушения, не выработаны и не закреплены четкие критерии, руководствуясь которыми представлялось бы возможным отнесение конкретного проступка к малозначительному.

Считаем, что наличие такого «пробела» в административном законодательстве является следствием несовершенного правового регулирования административно-правового института малозначительности совершенного правонарушения. Это в свою очередь порождает трудности в применении компетентными органами власти такого основания для освобождения от административной ответственности, отсутствует универсальный подход к определению малозначительности совершенного правонарушения, и, как следствие, отсутствует единая судебная практика, вплоть до противоположных позиций судов по рассмотренным однотипным делам.

Малозначительность совершенного правонарушения как возможность освобождения от административной ответственности трудно переоценить, так как для современного российского демократического общества с гуманистической направленностью она имеет значение. Но поскольку механизм правового регулирования рассматриваемой категории не совершенен, и у специалиста в области юриспруденции, и у правоприменителя, и у лица, совершившего правонарушение, возникают вполне логичные вопросы:

- что следует понимать под малозначительностью проступка?

- каковы универсальные критерии, по которым можно определить, является ли конкретное правонарушение малозначительным по характеру?

- любое ли правонарушение может быть признано малозначительным?

- каковы мотивы согласия или несогласия с применением института малозначительности при совершенном деянии?

- малозначительность: учет особенностей дела или повод избежать заслуженного наказания?

Если обратиться к опыту стран ближнего зарубежья в этой области, то, например, в Кодексе Республики Таджикистан об административных правонарушениях в ст. 25 дается определение малозначительного административного правонарушения и определяется его связь непосредственно с размером материального ущерба, которое оно повлекло (физическому лицу в размере до одного, а юридическому лицу - до десяти показателей для расчетов) [4]. Статья 64.1 КоАП Республики Казах- стан содержит примечание, в котором отмечается, что при квалификации совершенного правонарушения как малозначительного и решении вопроса об освобождении правонарушителя от ответственности, принимаются во внимание конкретные обстоятельства совершенного деяния, в том числе, личность правонарушителя, объект посягательства, а при наличии вреда - его размер [5].

Таким образом, административное законодательство в рассмотренных выше примерах учитывает необходимость определения некоторых признаков, наличие которых позволит признать правонарушение малозначительным, что вносит ясность для судьи, органа (должностного лица) при применении соответствующей статьи.

Нельзя не подчеркнуть тот факт, что на проблему применения малозначительности при рассмотрении дел об административных правонарушениях обращается внимание и субъектами административной юрисдикции в Российской Федерации.

Так, в постановлении Пленума Высшего Арбитражного Суда России указано, что малозначительность совершенного правонарушения является таковой при отсутствии существенной угрозы общественным отношениям и порядку, а судам при определении правонарушения как малозначительного необходимо исходить из конкретных обстоятельств его совершения. В то же время, такие обстоятельства как имущественное положение, личность самого правонарушителя, добровольное устранение им неблагоприятных последствий и возмещение ущерба не свидетельствуют о малозначительности деяния, а учитываются при назначении меры наказания в соответствии с КоАП РФ [6].

Постановлением Пленума Верховного Суда РФ определено, что малозначительное правонарушение выражено в действии (бездействии), формально содержащее признаки правонарушения, но с учетом характера правонарушения и роли правонарушителя, размера вреда и тяжести наступивших последствий, не представляющее существенного нарушения общественных отношений [7].

В свою очередь, Федеральная антимонопольная служба в письме «О применении статьи 2.9. КоАП РФ» отмечает, что критерии малозначительности административного правонарушения действующим законодательством РФ не определены, ввиду чего у уполномоченного на рассмотрение дела лица возникают вопросы о порядке применения соответствующей статьи. Также в письме указано, что акты Судов Российской Федерации формулируют понятие малозначительности, но не дают четких критериев ее применения, что обусловливает необходи- 
мость выработки единообразной практики применения ст. 2.9. КоАП РФ [8].

Для формирования более глубокого понимания сущности малозначительности правонарушения полагаем рассмотреть позиции ученого сообщества на этот счет.

Так, В.В. Степанов считает, что возможность применения малозначительности как основания освобождения от ответственности способствует учету конкретных обстоятельств каждого дела и позволяет избежать формальной определенности закона в негативном ключе, когда общий смысл и характер правовых норм не позволяет правоприменителю при рассмотрении спора учитывать многообразие различных сторон ситуации, не урегулированных законодательством [9, с. 3].

К.А. Ильясова считает целесообразным выделение таких основополагающих признаков, как: небольшой размер причиненного вреда, когда имеет место правонарушение с материальным составом или же небольшая угроза в рамках наступления последствий, когда речь идет о правонарушениях с формальным составом; определение путем анализа поведения правонарушителя его роли в совершении правонарушения как незначительной [10, с. 369].

О.В.Дербина при определении малозначительности совершенного правонарушения указывает внимание на следующие признаки: отсутствие существенного нарушения общественных отношений, формальное наличие всех признаков правонарушения, нецелесообразность привлечения лица к юридической ответственности [11, с. 31].

В. Ю. Пирогов говорит о том, что ст. 2.9. КоАП РФ может быть применена к любому составу правонарушения при условии, что проступок может быть отнесен к категории малозначительных, и при этом в отношении как физического, так и юридического лица [12, с. 69].

Согласимся с Т.П. Зюриной, указывающей на то, что с одной стороны, институт малозначительности имеет своим назначением учет конкретных особенностей дела, а с другой стороны, иногда его применение не является обоснованным, что позволяет правонарушителю избежать справедливого наказания [13, с. 97].

Приведем два примера по исследуемой теме из практики судов общей юрисдикции России и проанализируем их.

Решением Рудничного районного суда г. Прокопьевска прекращено производство по делу об административном правонарушении, предусмотренным ч. 2 ст. 12.27. КоАП РФ в отношении П., ввиду малозначительности совершенного правонарушения. Отменено постановление мирового судьи и наказание в виде лишения права управления транспортным средством (далее - ТС) сроком на 1 год. Судья отмечает то, что действия П. квалифицированы правильно в соответствии с вменяемой статьей, но установлено отсутствие существенного нарушения охраняемых общественных отношений, незначительность размера причиненного вреда и тяжести наступивших последствий (столкновение имело место со стоявшим во дворе ТС, в котором не было людей, оно являлось незначительным, никто не пострадал и каких-либо неблагоприятных последствий не наступило). При этом взята во внимание роль правонарушителя в содеянном (проступок совершен впервые; после того, как личность П. была установлена сотрудниками ГИБДД, скрываться П. не пыталась; вину признала полностью).

Постановлением Верховного суда Республики Саха (Якутия) оставлено без изменения постановление мирового судьи, решение судьи Якутского городского суда, вынесенные по делу об административном правонарушении, предусмотренным ч. 2 ст. 12.27. КоАП РФ в отношении $\mathrm{T}$.

Сохранено наказание в виде лишения права управления ТС сроком на 1 год, определена невозможность применения ст. 2.9. КоАП РФ в данной ситуации. Суд отметил то, что малозначительность правонарушения имеет место при отсутствии существенной угрозы охраняемым общественным отношениям. Оставление Т. места ДТП является грубым нарушением ПДД, поэтому отсутствуют всякие основания квалифицировать действия Т. как малозначительные, ввиду чего не имеется возможности применения ст. 2.9. КоАП РФ.

Какие выводы мы можем сделать, проанализировав данные решения? Очевидно то, что предметом рассмотрения являются две схожие ситуации, предусмотренные ч. 2 ст. 12. 27 КоАП РФ и связанные с оставлением водителем места дорожно-транспортного происшествия, участником которого он являлся. Исходя из содержания индивидуально-правовых актов, вынесенных судами, в обеих ситуациях не причинен существенный вред общественным отношениям, охраняемым нормами права. В результате происшествий никто из водителей и иных участников дорожного движения не пострадал, правонарушители не отрицают своей вины в содеянном, налицо отсутствие каких-либо тяжелых последствий как итога деяний.

Примечательно то, что в первой ситуации судья рассмотрел дело с разных сторон и, основываясь на личных внутренних убеждениях, воспользовался правом 
освободить П. от административной ответственности, так как посчитал совершенный проступок малозначительным.

Во второй ситуации, напротив - судья категорично считает, что оставление места дорожно-транспортного происшествия - грубое нарушение ПДД и лицу, совершившему правонарушение, следует исполнить назначенное наказание. Из содержания постановления видно, что правоприменителем не взяты во внимание характер и размер причиненного вреда, роль правонарушителя в содеянном, форма его вины, незначительная тяжесть последствий правонарушения и иные аспекты, которые учитываются в ситуации № 1. Соответственно, если бы дело № 2 изучал судья Рудничного районного суда г. Прокопьевска, то вполне возможно, ставился и рассматривался бы вопрос об освобождении Т. от административной ответственности ввиду малозначительности совершенного деяния и о прекращении в отношении него производства.

Еще раз подчеркнем, что такие обстоятельства являются следствием отсутствия закрепления в административном законодательстве термина малозначительности правонарушения или же критериев, по которым можно было бы квалифицировать то или иное правонарушение как малозначительное.

Резюмируя, считаем нужным выделить следующие признаки, которые необходимо учитывать при вопросе об отнесении правонарушения к малозначительному:

1. формальное содержание всех признаков административного правонарушения (сам факт совершения правонарушения, общественная опасность, противоправность, виновность, наказуемость);

2. отсутствие сущуественного нарушения общественных отношении, охраняемых законом (например, возможность применения малозначительности должна исключаться при вменении такой санкции в отношении нарушителя как административный арест, выдворение, административное приостановление деятельности, по своей правовой природе свидетельствующих о высокой общественной опасности деяний, за которые применяются подобные наказания;

3. небольшой размер причиненного вреда, отсутствие серьезных негативных последствий (при материальном составе), угрозы наступления таких последствий (при формальном составе) от совершенного правонарушения;

4. учет роли лица в содеянном (например, наличие вины в форме умысла явно не может свидетельствовать о малозначительности совершенного правонарушения также, как и его повторность).
5. несоразмерность наказания, предусмотренного санкиией статьи характеру совершенного правонарушения (прослеживается связь с формальным наличием всех признаков правонарушения, но с учетом рассмотренных ранее критериев, наказание является слишком жестким для конкретного правонарушителя).

На основании проведенного исследования, разъяснений органов государственной власти, рассмотренных мнений специалистов в области административного права и положительного опыта зарубежных стран, считаем целесообразным включить в статью 2.9. КоАП РФ часть 2 и дополнить ее следующим положением: малозначительным является проступок, формально содержащий все признаки административного правонарушения, но с учетом характера правонарушения, незначительного размера причиненного вреда, отсутствия серьезных негативных последствий или угрозы их наступления, роли правонарушителя и несоразмерности наказания, предусмотренного санкцией статьи характеру совершенного деяния, не представляющий существенного нарушения общественных отношений, охраняемых государством.

В заключение всего вышесказанного важно отметить то, что категория малозначительности в рассматриваемой области является оценочной, что предопределяет необходимость учета конкретных обстоятельств каждого дела. Но в то же время понятие малозначительности как основания освобождения от юридической ответственности является собирательным, что требует от правоприменителя учета универсальных критериев, наличие которых позволит квалифицировать совершенное правонарушение как малозначительное.

Отсутствие прямых ссылок и указаний на признаки, позволяющие охарактеризовать проступок как малозначительный, заставляет юрисдикционные органы определять их в каждом случае самостоятельно, способствует субъективному принятию решения и создает широкое поле для интеллектуального маневра правоприменителя: от признания правонарушения малозначительным до отказа от него.

Закрепление в административном законодательстве унифицированного понятия или критериев малозначительности как возможности освобождения от юридической ответственности повлекла бы за собой более глубокое понимание правоприменителем сущности данного административно-правового института, создала бы основу для его дальнейшего развития и способствовала бы выработке единообразного применения положений ст. 2.9. КоАП РФ. 


\section{ЛИТЕРАТУРА}

1. Конституция Российской Федерации (принята всенародным голосованием 12.12.1993) (с учетом поправок, внесенных Законами РФ о поправках к Конституции РФ от 30.12.2008 № 6-ФК3, от 30.12.2008 № 7-ФК3, 0т 05.02.2014 № 2-ФК3, от 21.07.2014 № 11-ФК3) // Собрание законодательства РФ, 04.08.2014, № 31, ст. 4398.

2. Кодекс Российской Федерации об административных правонарушениях: Федеральный закон Российской Федерации от 30.12 .2001 № 195-Ф3 (ред. от 01.04.2020) // Российская газета, № 256, 31.12.2001.

3. Кодекс РСФСР об административных правонарушениях: Федеральный закон РСФСР от 20.06.1984 (ред. от 20.03.2001) // Ведомости Верховного Совета РСФСР. 1984. № 21. Ст. 909.

4. Кодекс Республики Таджикистан об административных правонарушениях: принят Законом Республики Таджикистан от 31.12 .2008 № 455 (с изм. и доп. на 02.01.2020)

5. Кодекс Республики Казахстан об административных правонарушениях от 05.07.2014 N235-V (с изм. и доп. на 06.05.2020) // Казахстанская правда, 12.07.2014, № 135, ст. 27756.

6. 0 некоторых вопросах, возникших в судебной практике при рассмотрении дел об административных правонарушениях: Постановление Пленума ВАС РФ от 02.06.2004 N10 (ред. от 21.12.2017) // Вестник ВАС РФ, № 8, 2004.

7. 0 некоторых вопросах, возникающих у судов при применении Кодекса Российской Федерации об административных правонарушениях: Постановление Пленума Верховного Суда РФ от 24.03.2005 N5 (ред. от 19.12.2013) // Бюллетень Верховного Суда РФ, № 6, 2005.

8. О применении статьи 2.9 Кодекса Российской Федерации об административных правонарушениях: <Письм0> ФАС России от 23.09.2016 № ИА/65682/16.

9. Степанов В. В. Малозначительность правонарушения в российском праве: автореф. дис. ... канд. юрид. наук.: М., 2009. 27 с.

10. Ильясова К. А. Малозначительность правонарушения и его критерии // Аллея науки. 2017. Т. 2. № 16. С. 368-371.

11. Дербина 0.В Проблемные вопросы определения признаков малозначительности административного правонарушения // Вестник института: преступление, наказание, исправление. 2017. № 1 (37). С. 31-33.

12. Пирогов В. Ю. Критерии признания административного правонарушения малозначительным // Вестник Тюменского государственного университета. Социально-экономические и правовые исследования. 2013. № 3. С. 67-74.

13. Зюрина Т.П. К вопросу о малозначительности административных правонарушений // Административное и административно-процессуальное право: актуальные проблемы. Ч. 2. М., 2005, С. 96-98.

( Карпов Олег Вячеславович ( okarp67@mail.ru ), Лукашина Ангелина Эльчиновна ( Lukashina.angelina@mail.ru ).

Журнал «Современная наука: актуальные проблемы теории и практики»

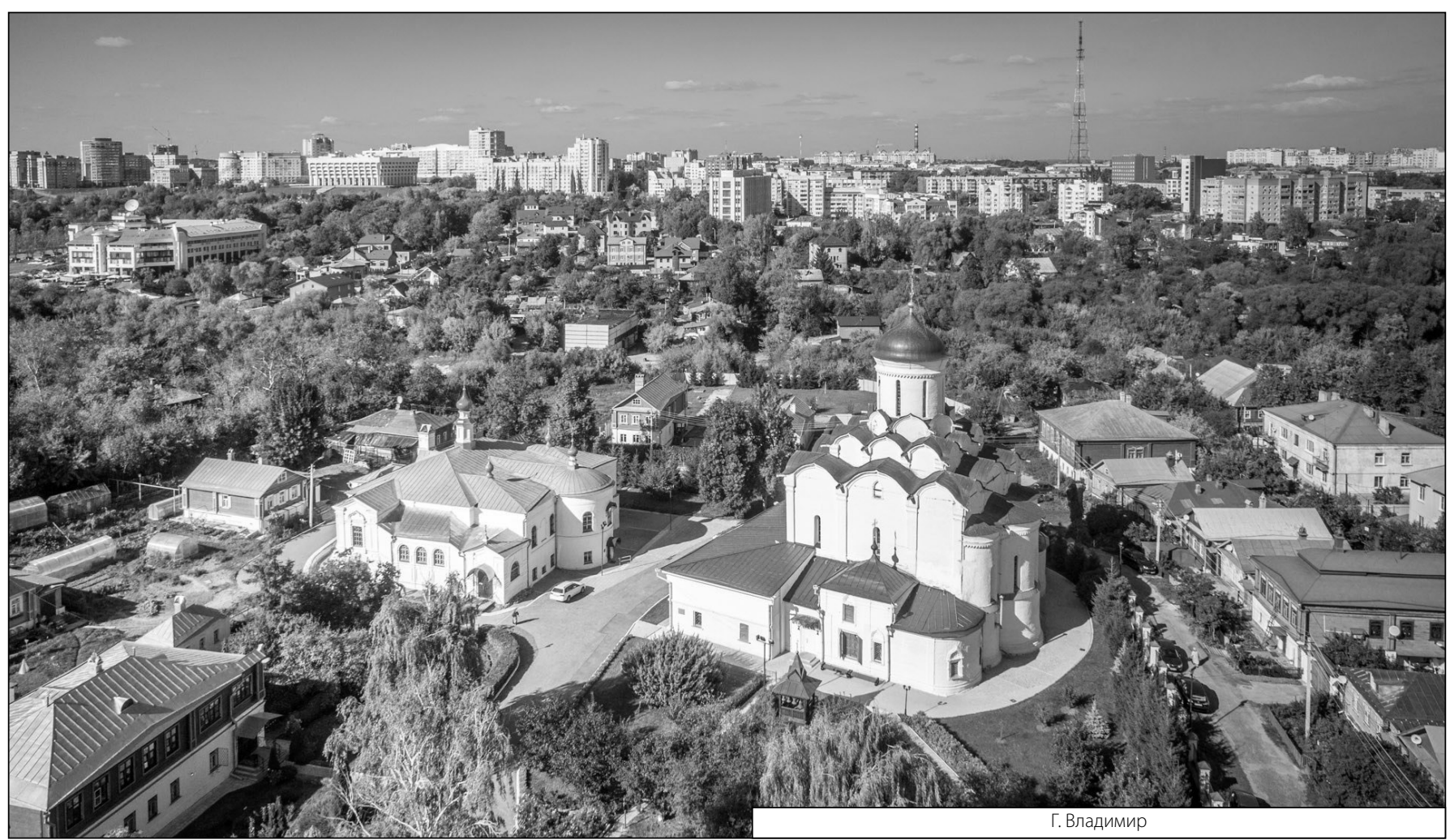

